\title{
Surgical Excision and Immediate Postoperative Radiotherapy versus Cryotherapy and Intralesional Steroids in the Management of Keloids: A Prospective Clinical Trial
}

\author{
Maryam Emad ${ }^{a}$ Shapour Omidvarib ${ }^{b}$ Ladan Dastgheib ${ }^{a, d}$ Afshin Mortazavi $^{a}$ \\ Haleh Ghaem ${ }^{c}$ \\ Departments of a Dermatology, ${ }^{\mathrm{b}}$ Radiation Oncology, ${ }^{\mathrm{c}}$ Epidemiology, and ${ }^{\mathrm{d}}$ Autoimmune Diseases Research Center, \\ Shiraz University of Medical Sciences, Shiraz, Iran
}

\section{Key Words}

Cryotherapy • Intralesional steroid treatment $\cdot$ Keloids •

Radiotherapy $\cdot$ Steroids

\begin{abstract}
Objective: To compare the efficacy and tolerability of surgical excision and radiotherapy with those of cryotherapy and intralesional steroid treatment of keloids. Subjects and Methods: Twenty-six patients with a total of 76 keloids were enrolled in this study. Nineteen patients with 44 keloids underwent surgical excision combined with immediate 12-Gy irradiation (group A) while the remaining 9 patients with 32 keloids received multiple sessions of intralesional steroid treatment after cryotherapy which continued until flattening of lesion(s) occurred (group B). Two patients were included in both treatment groups. All patients were followed up at regular intervals for at least 1 year. Results: In both treatment groups, keloids responded well without any major side effect. While patients of group A were all satisfied, those of group B (with a mean number of treatment sessions of 5.84 \pm 2.51) experienced more side effects, a more prolonged course, a higher recurrence rate and less satisfaction. Conclusion: This study showed that surgery plus immediate
\end{abstract}

postoperative irradiation was an effective and relatively safe choice for treatment of keloids. Although cryotherapy combined with intralesional steroids was associated with more side effects and higher relapse rates, it could be a good choice for small and newly formed keloids.

Copyright $\odot 2010$ S. Karger AG, Basel

\section{Introduction}

A keloid has been defined as a benign growth of dense fibrous tissue arising from an abnormal healing response to a cutaneous injury, extending beyond the original borders of the wound. Although keloids are frequently asymptomatic, many patients complain of pruritus and/ or tenderness [1]. Multiple etiological factors have been proposed for the complex pathogenesis of keloids. Transforming growth factor- $\beta$ (TGF- $\beta$ ) plays a significant role in the transcription of collagen and collagenase in fibroblasts. Although TGF- $\beta_{1}$ and TGF- $\beta_{2}$ can stimulate scar formation, TGF- $\beta_{3}$ may either induce or reduce scar production. Another factor which may have a role in keloid formation is nutritional deficiency in fatty acids [2].

\section{KARGER}

Fax +4161306 1234

E-Mail karger@karger.ch

www.karger.com (c) 2010 S. Karger AG, Basel

1011-7571/10/0195-0402\$26.00/0

Accessible online at:

www.karger.com/mpp
Ladan Dastgheib

Department of Dermatology

Saadi Hospital, Zand Avenue

Shiraz (Iran)

Tel. +98 711235 7547, Fax +98 711231 9049, E-Mail dastghl@sums.ac.ir 
Most of the treatment modalities, which can be divided into surgical and non-surgical ones, can lead to relapse if used alone. Because there is no gold standard for keloid treatment, this study was designed to compare the efficacy and safety of surgical excision with adjuvant irradiation versus cryotherapy and intralesional steroids.

\section{Subjects and Methods}

This is a non-randomized prospective clinical trial which was approved by the Research and Ethics Committee of Shiraz University of Medical Sciences, Shiraz, Iran. The study was conducted in the Saadi Dermatology Clinic and the Department of Radiation Oncology, Namazi Hospital, on patients suffering from keloids. Twenty-six patients ( 13 women and 13 men) with a total number of 76 keloids were enrolled after obtaining written informed consent.

They were divided into two groups according to the previous treatment modality and patients' desire (all of them were informed about the procedures, their advantages and side effects before selection). Patients in group A (19 patients) underwent surgical excision and immediate local radiotherapy; group B patients $(n=9)$ were treated with cryotherapy and intralesional triamcinolone acetonide. However, 2 patients were included in both treatment groups. Baseline demographic and clinical characteristics of the patients are presented in table 1.

The criteria for exclusion were previous treatment within the recent 2 months, any known significant abnormality of hemostasis, need for skin flaps, grafts or tissue expander after surgical excision, and loss to follow-up. Further, exclusion criteria for group A were age $<18$ years and keloids on the neck or upper chest area to avoid possible late complications of radiation exposure.

All patients in group A and 9 of 20 from group B completed the study. The other 11 patients of group B dropped out because of associated pain or frequent visits needed for cryotherapy plus intralesional steroid treatment.

\section{Treatment Schedules}

Group A. All the patients had complete extralesional surgical excision prior to adjuvant radiotherapy. Under sterile condition and local anesthesia with lidocaine $2 \%$, the keloids were excised and margins were undermined. Then subcutaneous fat and deep dermis were approximated with subcutaneous interrupted sutures using $3 / 0$ to $5 / 0$ vicryl, and epidermis was closed by interrupted sutures using $3 / 0$ to $5 / 0$ nylon under tension-free condition. All the patients received prophylactic antibiotic (cephalexin capsules $500 \mathrm{mg}$ orally every $6 \mathrm{~h}$ started $2 \mathrm{~h}$ before surgery for 5 days). Postsurgical irradiation was started within $48 \mathrm{~h}$ after surgery. The total dose of radiation was $12 \mathrm{~Gy}$ in three fractions (one fraction per week), which was given by a superficial X-ray therapy machine (Siemens Stabilipan: $120 \mathrm{kV}, 10 \mathrm{~mA}, 2 \mathrm{~mm}$ Al filtration, $4 \mathrm{~mm} \mathrm{Al}$ half-value layer). The field of irradiation included the surgical line of excision extending $1 \mathrm{~cm}$ from its margin. Sutures were removed 10-20 days after surgery ( 1 week later than standard due to lack of optimal repair) depending on the anatomical location of the wound to avoid suture marks.
Table 1. Demographic and clinical profile of the two patient groups

\begin{tabular}{lcl}
\hline Characteristics & $\begin{array}{l}\text { Group A } \\
(\mathrm{n}=19)\end{array}$ & $\begin{array}{l}\text { Group B } \\
(\mathrm{n}=9)\end{array}$ \\
\hline Keloids, $\mathrm{n}$ & 44 & 32 \\
Mean age (range), years & $28.3(18-42)$ & $30(16-45)$ \\
Mean duration (range), & & \\
$\quad$ months & $29.1(3 \mathrm{~m}-23 \mathrm{y})$ & $18(3 \mathrm{~m}-15 \mathrm{y})$ \\
Mean diameter (range), cm & $5.7(1-22)$ & $4.6(1-15)$ \\
Location, $\mathrm{n}$ & & \\
$\quad$ Trunk & 14 & 27 \\
$\quad$ Upper limbs & 14 & 1 \\
$\quad$ Lower limbs & 4 & 4 \\
$\quad$ Ear lobe & 7 & 1 \\
$\quad$ Scalp & 1 & - \\
$\quad$ Neck & 4 & 1 \\
Cause of keloids, $\mathrm{n}$ & & 4 \\
$\quad$ Surgery & 6 & - \\
Burn (chemical) & 2 & 3 \\
$\quad$ Trauma & 8 & 1 \\
$\quad$ Acne & 1 & \\
Spontaneous & 2 & \\
\hline
\end{tabular}

$\mathrm{n}=$ Number of keloids; $\mathrm{y}=$ years; $\mathrm{m}=$ months. Two patients were included in both groups. Three keloids with extreme duration, i.e. 15, 20 and 23 years, were not considered when calculating the mean duration.

Group B. The patients underwent cryotherapy by liquid nitrogen with a cotton swab until appearance of a 1-mm halo of freezing, which usually took at least 10-20 s. Then, using a 28-gauge needle, $10 \mathrm{mg} / \mathrm{ml}$ of triamcinolone acetonide (Triamhexal; Hexal, Germany) were injected intradermally into the keloid, with the amount depending on the size of the keloid and its depth considered in each session (maximum $40 \mathrm{mg}$ ) every 20 days until complete flattening was achieved or discontinued if no further improvement was seen during the last 3 sessions.

\section{Patient Assessment}

Each patient was followed in the treatment period, then every 3 months to at least 1 year, and every 6 months thereafter up to 2 years after treatment, to evaluate efficacy of treatment and any side effects. The mean duration of the follow-up period was 19 months. The response rate was evaluated visually by measuring keloid depth and any change in the symptoms experienced by the patients. Complete remission was defined as complete disappearance of keloid, partial remission as mild relapse with $<2 \mathrm{~mm}$ elevation confined to the line of excision and treatment failure as $>2 \mathrm{~mm}$ elevation extending from the initial line of surgery. The patients' subjective self-assessment for treatment satisfaction was also recorded as satisfied, partially satisfied and unsatisfied. At the end of the trial, the data gathered from the two treatment groups were compared. 
Table 2. Rate of response to treatment of the keloids in each group

\begin{tabular}{lrc}
\hline & Group A & Group B \\
\hline Complete remission & $31(70.4 \%)$ & $22(68.8 \%)$ \\
Partial remission & $5(11.4 \%)$ & $1(3.1 \%)$ \\
Failure & $8(18.2 \%)$ & $9(28.1 \%)$ \\
\hline
\end{tabular}

Table 3. Patients' self-assessment of treatment

\begin{tabular}{lcl}
\hline Self-assessment & Group A & Group B \\
\hline Satisfied & $17(89.5 \%)$ & $6(66.7 \%)$ \\
Partially satisfied & $2(10.5 \%)$ & $2(22.2 \%)$ \\
Unsatisfied & $0(0.0 \%)$ & $1(11.1 \%)$ \\
\hline
\end{tabular}

Two patients are included in both groups.

Table 4. Complications observed in each treatment group

\begin{tabular}{llc}
\hline Complications & Group A & Group B \\
\hline Hyperpigmentation & $5(11.4 \%)$ & 0 \\
Hypopigmentation & $3(6.8 \%)$ & $3(9.4 \%)$ \\
Ulceration + necrosis & 0 & $10(31.2 \%)$ \\
Telangiectasia & $1(2.3 \%)$ & $6(18.8 \%)$ \\
Infection and wound dehiscence & $2(4.5 \%)$ & 0 \\
\hline Total & $11(25.0 \%)$ & $19(59.4 \%)$ \\
\hline
\end{tabular}

\section{Results}

Treatment results of both groups are summarized in tables 2 and 3.

In 8 keloids in group $\mathrm{A}$, treatment had failed, but keloid depths were less than one third of their initial depths, including 2 lesions with postsurgical wound infection and dehiscence and 2 keloids located on highly mobile joints (one on the deltoid and the other on the elbow joint). Of the 9 non-responding lesions in group B, 3 did not respond after at least 3 treatment sessions. Keloid-associated symptoms such as pain and itching improved in all lesions in group A, and also in 29 of 32 (90.6\%) keloids in group B.

In 3 patients with spontaneous keloid, 2 showed very good response to surgery and radiotherapy, but the 3rd patient did not respond to 14 sessions of intralesional steroid treatment after cryotherapy. In group $\mathrm{B}$, the best results were seen in keloids $<2 \mathrm{~cm}$ in size and in new cases
Table 5. Total number of treatment sessions in patients of group B (cryotherapy plus intralesional steroid treatment)

\begin{tabular}{lcr}
\hline Sessions & \multicolumn{2}{c}{ Keloids } \\
\cline { 2 - 3 } & $\mathrm{n}$ & $\%$ \\
\hline 3 & 2 & 6.3 \\
4 & 15 & 46.9 \\
5 & 1 & 3.1 \\
6 & 10 & 31.2 \\
14 & 4 & 12.5 \\
\hline Mean 5.8 & 32 & 100 \\
\hline
\end{tabular}

without a history of previous treatment failure (not the recurrent ones).

Hypo- and hyperpigmentation were the most common side effects noticed in group A (8/44), while in 16 of 32 lesions of group B, small areas of the skin were involved with ulceration and necrosis, or persistent telangiectasia (table 4). The mean number of treatment sessions for group B was 5.84 (range 3-14 sessions; table 5).

\section{Discussion}

The results of our study showed that in the treatment of keloids surgery plus immediate radiotherapy was more efficacious and safe than cryotherapy plus intralesional steroid injection. Patients undergoing surgery and adjuvant irradiation may be more satisfied probably due to the shorter treatment period, less pain and disappearance of the keloids after the 1st day of treatment.

Our results confirmed previous studies $[3,4]$ that the recurrence rate in patients who received postexcisional immediate radiotherapy was dependent on the site of the keloid and higher skin stretch tension, but not influenced by its length. In addition, postsurgical wound infection and dehiscence resulted in relapse which could be prevented by proper surgical sterile technique.

The superficial low-dose X-ray therapy we used yielded a combined complete and partial remission of $81.8 \%$ (table 2), being consistent with the 65-99\% reported for other machines that include electron beam and high-dose brachytherapy [5]. Although the risk of developing secondary malignancy is extremely low in patients treated with low-dose radiotherapy for keloid, it is necessary to use small radiation fields so that the surrounding and underlying normal tissue can be spared. However, Botwood 
et al. [6] reported 1 patient with a breast carcinoma 29 years after receiving low-dose radiotherapy for a severe keloid on the previous burn sites. In children irradiation should be avoided due to the higher risk of cancer development with radiotherapy in their growing tissue [3].

Although using cryotherapy before steroid injection induces edema thereby facilitating injection, prolonged healing, multiple treatments requiring multiple painful injections and need for large steroid doses may render it impractical for large or multiple keloids [1]. However, excellent results with minimal side effects can be achieved in the absence of long-term relapse and in small keloids lesions [7]. Irrespective of the fact that cryotherapy and intralesional steroids was associated with higher rates of side effects and relapses, it can be a good choice for small, newly formed keloids without a history of treatment failure.

Other therapies [3, 8-11] have been investigated, and various relapse rates and side effects have been found. Boutli-Kasapidou et al. [8] treated their patients with monthly cryotherapy and three times daily local application of silicone gel for 1 year and monthly intralesional triamcinolone acetonide injection for 3 months. They concluded that this polytherapy may be effective in the treatment of keloid scars. Gupta and Kumar [9] reported $>75 \%$ flattening of keloids in 7 of 12 patients with multiple sessions of intralesional cryotherapy with lumbar puncture and/or hypodermic needles. Weekly intralesional injection of 5-fluorouracil for up to 4 months can result in flattening of keloids in $>50 \%$ of patients. Other suggested treatments such as intralesional injection of interferon $\alpha-2 \beta$ or bleomycin and postoperative topical imiquimod cream may need reevaluation in a larger patient cohort and for a longer term to assess their therapeutic benefits and side effect [3]. Although the use of lasers for the treat- ment of keloids has been almost disappointing, pulsed dye laser plus intralesional steroid injection may soften the lesions [10]. Berman et al. [11] used intralesional etanercept or triamcinolone acetonide and compared treatment response using 12 clinical, physical and cosmetic parameters in two groups. They found no statistical difference between the two treatment arms. A recent study suggests [2] that treatment with topical, intralesional and oral fatty acids may have a potential benefit in keloid management. Overall, there is no universally accepted treatment for keloids and its management has to be adapted to the patient's age and keloid distribution, size and thickness, consistency of the lesion and associated inflammation. Combination treatment may be the best choice [1].

Although our study evaluated a good sample size with adequate follow-up, and treatment groups seemed to be almost equivalent at baseline, lack of randomization might have caused a selection bias.

\section{Conclusion}

The results of this study showed that surgery plus immediate postoperative irradiation was an effective and relatively safe choice for treatment of keloids. Treatment consisting of cryotherapy and intralesional steroids was associated with higher rates of side effects and relapses. However, this kind of treatment could be a good choice for small, newly formed keloids without previous treatment failure or those located near the thyroid gland, and for patients refusing surgery and children.

Our results should be confirmed in a randomized clinical trial with equally distributed patient numbers and a longer follow-up period.

\section{References}

$\checkmark 1$ Robles DT, Moore E, Draznin M: Keloids: pathophysiology and management. Dermatol Online J 2007;13:9.

2 Louw L: The keloid phenomenon: progress toward a solution (Review). Clin Anat 2007; 20:3-14.

-3 Bishof M, Krempien R, Debus J, Treiber M: Postoperative electron beam radiotherapy for keloids: objective findings and patient satisfaction in self-assessment. Int J Dermatol 2007;48:971-975.

-4 Wagner W, Alfrink M, Micke O, Schäfer U, Schüller P, Willich N: Results of prophylactic irradiation in patients with resected keloids - a retrospective analysis. Acta Oncol 2000;39:217-220.
5 Al-Attar A, Mess S, Thomassen JM, Kauffman CL, Davison SP: Keloid pathogenesis and treatment. Plast Reconstr Surg 2006;117: 286-300.

6 Botwood N, Lewanski C, Lowdell C: The risks of treating keloids with radiotherapy. Br J Radiol 1999;72:1222-1224.

7 Mutalik S: Treatment of keloids and hypertrophic scars (review). Indian J Dermatol Venereol Leprol 2005;71:3-8.

-8 Boutli-Kasapidou F, Tsakiri A, Anagnostou E, Mourellou O: Hypertrophic and keloid scars: an approach to polytherapy. Int J Dermatol 2005;44:324-327.
9 Gupta S, Kumar B: Intralesional cryotherapy using lumbar puncture and/or hypodermic needles for large, bulky, recalcitrant keloids. Int J Dermatol 2001;40:349-353.

10 Connell PG, Harland CC: Treatment of keloid scars with pulsed dye laser and intralesional steroid. J Cutan Laser Ther 2000;2: 147-150.

11 Berman B, Patal JK, Perez OA, Viera MH, Amini S, Block S, Zell D, Tadicherla S, Villa A, Ramirez C, De Araujo T: Evaluating the tolerability and efficacy of etanercept compared to triamcinolone acetonide for the intralesional treatment of keloids. J Drugs Dermatol 2008;7:757-761. 